\title{
Políticas Públicas e Segurança Social: Da Proteção à (Des)Coesão Social
}

\author{
Joaquim Croca Caeiro* \\ * Instituto Superior de Ciências Sociais e Políticas - Universidade de Lisboa, Portugal
}

\begin{abstract}
Resumo
O texto que se apresenta pretende analisar a segurança social, enquanto instrumento do Estado, para a garantia da satisfação de necessidades coletivas dos cidadãos, sobretudo as que resultam da sua dimensão social e a repercussão que ela pode ter na promoção da coesão social em Portugal. Entendida a coesão social como a dialética entre mecanismos instituídos de inclusão e exclusão social e as respostas, perceções e disposições dos cidadãos, em face do modo como esses mecanismos funcionam. A coesão social está assim, associada a um acesso equilibrado da população aos resultados do progresso económico, mediante políticas corretivas da distribuição desigual de rendimentos e à aposta na qualidade de vida dos cidadãos. Entendida assim, a conclusão a que chegámos é a de que a coesão social não é alcançável apenas com o recurso ao elemento privilegiado para o efeito: a Segurança Social. Esta, por si só, não consegue garantir o conjunto das necessidades que a determinam nomeadamente, a redução das desigualdades, a eliminação da pobreza e o aumento da participação dos cidadãos na sociedade.
\end{abstract}

Palavras-chave: segurança social; coesão social; inclusão e exclusão; políticas de distribuição

\begin{abstract}
This article aims at analysing social welfare as a state instrument guaranteeing the satisfaction of the collective needs of citizens, especially those resulting from their social dimension and the repercussions it can have on the promotion of social cohesion in Portugal. The social cohesion is extended as a dialectic between instituted mechanisms of social inclusion and exclusion and the responses, perceptions and citizens' dispositions regarding the ways these mechanisms work. Social cohesion is thus associated to an even access to economic processes results through corrective policies of unequal income distribution and a commitment to quality of life standards. It argues that social cohesion is not attainable through the use of the privileged element for the effect: the Social Welfare mechanisms provided by the state. They are not able, on their own, to guarantee the set of responses needed, namely, reducing inequalities, eliminating poverty and increasing citizen participation in society.
\end{abstract}

Keywords: social welfare; social cohesion; inclusion and exclusion; distribution policies 


\section{Introdução}

Pretendemos, neste texto, de forma geral, discutir a coesão social mediante uma exposição sintética e atento o conceito de políticas públicas sociais redistributivas. Em concreto, aferir sobre a influência da Segurança Social, enquanto instrumento privilegiado para a redução das desigualdades sociais e da pobreza, elementos determinantes para a concretização da coesão social.

A coesão social enquanto conceito dinâmico e evolutivo e, ao mesmo tempo, de largo espetro, tem de analisar-se tendo em consideração, para além dos indicadores de rendimento e desigualdade, outros instrumentos de avaliação, nomeadamente, indicadores de natureza social, que caracterizam a dimensão de cidadania, emprego e rendimento.

Importa questionar, se de facto a coesão social existe, poderá vir a existir em alguma circunstância, ou é uma simples perspetiva utópica utilizada como estratégica ideológico-política para sustentar os "discursos" da promoção do desenvolvimento humano e social e para a preservação da estabilidade e da paz social?

Neste contexto, abordaremos sumariamente, as políticas públicas sociais redistributivas, onde se insere, a dimensão instrumental da Segurança Social, analisando depois o seu contexto, evolução, desenvolvimento e a sua preponderância no domínio da proteção social e da redução das desigualdades e combate à pobreza.

A abordagem metodológica, com recurso a fontes primárias, consubstanciadas nos recursos usados pelo poder para concretizar a sua influência e autoridade, a saber, o conjunto da legislação produzida ao longo dos tempos, para a organização e funcionamento da Segurança Social, a fontes secundárias, utilizadas sob a forma de artigos, livros e outros documentos, que refletem as posições dos que, de forma geral ou específica, se debruçaram sobre o assunto que ora nos preocupa. E, numa dimensão mais quantitativa, analisámos as medidas de proteção social, com recurso a indicadores estatísticos e um conjunto bibliográfico para sustentar as nossas perspetivas.

\section{As Políticas Públicas de Proteção Social}

As políticas públicas enquanto ações levadas a efeito pelo Estado ou outras entidades privadas ou semipúblicas em quem eventualmente deleguem, para a resolução de problemas que afetam os cidadãos de uma forma coletiva e a promoção do seu bem- estar, permitem pensar a coesão social e minorar as desigualdades existentes entre os cidadãos.

As políticas públicas costumam ser classificadas como:

1. Distributivas, quando não consideram a limitação de recursos públicos e pretendem resolver os problemas de apenas uma parte da sociedade, especialmente a distribuição de subsídios a determinados tipos de grupos sociais específicos; 
2. Redistributivas, quando se pretende resolver os problemas de determinados segmentos específicos da sociedade a partir de recursos provenientes de outros grupos sociais;

3. Regulatórias, as que o Estado e demais entidades públicas utilizam para aferir da forma como as entidades privadas e quase-públicas se comportam no mercado, regulando e fiscalizando a sua atividade através do recurso a normas, regras e outros procedimentos legais (Pereirinha, 2016).

As políticas públicas redistributivas, pelas quais o Estado ou outras entidades em quem delegue recorrem a um conjunto de mecanismos de proteção social visando a satisfação de necessidades coletivas. A redistribuição faz-se por intermédio dos impostos e com recurso às políticas públicas contra a desigualdade e pobreza, nas quais se integram as de educação, formação e qualificação profissional, pobreza e exclusão social (Pereirinha, 2016).

Neste sentido, consideramos as prestações sociais como elementos de recurso do Estado para a promoção da coesão social, sendo no caso português, uma das principais prestações sociais do ponto de vista redistributivo as pensões, que incorporando os mecanismos da solidariedade intergeracional e de base profissional pretendem garantir prestações pecuniárias substitutivas de rendimentos de trabalho perdido (Coelho, 2013).

Estas pensões, são promovidas por duas entidades públicas, a Segurança Social e a Caixa Geral de Aposentações. Às primeiras, têm direito os trabalhadores por conta de outrem ou legalmente equiparados e os trabalhadores independentes. As segundas são concedidas aos trabalhadores da Administração Pública.

\section{A Segurança Social. Evolução e Atualidade}

A necessidade de proteção social é uma evidência, não apenas histórica, mas também contemporânea, para que os indivíduos possam de uma forma geral, garantir a satisfação das suas necessidades sociais e, ao mesmo tempo, aceder a um mínimo de bem-estar.

A satisfação daquelas necessidades foi, a partir do final da II Guerra Mundial, realizada pela intervenção do Estado, através dos designados direitos sociais, pese embora o facto da génese de tal intervenção radicar na criação na Alemanha, pela intervenção de Otto von Bismarck, dos seguros sociais obrigatórios em 1882.

Os seguros sociais obrigatórios, corporativos e sem intervenção direta do Estado, tinham o intuito de proteger o proletariado que grassava na Europa e de controlar a pressão revolucionária que ganhou importância pela questão social, com o aumento dos simpatizantes e militantes no partido comunista a partir meados do século XIX, o que ameaçava os países mais industrializados da época (Caeiro, 2015).

Com natureza corporativa, protegia apenas os operários em atividade laboral, excecionando as suas famílias e o objeto da proteção não ia além de alguma proteção na saúde, na morte e na invalidez. Estes seguros sociais, acabariam por se estender 
a toda a Europa industrializada mantendo, todavia, a mesma perspetiva e o mesmo objeto, até ao final da II Guerra Mundial.

O fim da II Guerra Mundial, a influência da Grande Depressão, o New Deal, as sequelas da guerra e as alterações político-ideológicas verificadas, contribuíram para a necessidade de reorganizar a estrutura social dos Estados europeus. O processo de viragem iniciou-se no Reino Unido, com o Relatório Beveridge, em 1944, a transformação dos mecanismos de proteção social bismarckianos de natureza corporativa, numa dimensão universal, tutelada e financiada pelo Estado, abarcando a Saúde, a Educação e a Segurança Social. Nasciam os direitos sociais caraterísticos do século $\mathrm{xx}$ e que tinham como intuito principal promover e garantir o bem-estar dos cidadãos (Caeiro, 2015).

Este Estado de bem-estar havia de se desenvolver ao longo dos anos 50, 60 e 70, traduzindo-se num acréscimo da quantidade de direitos sociais criados e consubstanciando-se num aumento dos custos com a sua garantia e uma cada vez maior intervenção do Estado na sua organização.

A crise do Estado de bem-estar, a partir de meados da década de 70 do século $\mathrm{xx}$, marcaria de forma definitiva os anos que se seguiram, obrigando à criação de mecanismos de reforma mais ou menos profundos e à adoção de modelos políticos e ideológicos dos quais se destacam a New Public Management, a Reinventing Government e a New Public Services (Loureiro, 2010).

As políticas sociais e a preocupação com a proteção social registam um percurso evolutivo relacionado com os períodos político-ideológicos mais marcantes da vida do país e, sobretudo, desde a implantação do Estado Novo até à atualidade.

Desde cedo, o governo procurou colmatar os problemas económicos e sociais que haviam marcado a I República, com a inscrição constitucional de alguns pressupostos económicos e sociais do Estado e a publicação do Estatuto do Trabalho Nacional, sob os auspícios da organização corporativa e cuja influência radicava na Encíclica Rerum Novarum, da autoria do Papa Leão XII e, posteriormente, nos teóricos do corporativismo, como G. Gentile e M. Manoilesco (Caeiro, 2015).

Os pressupostos constitucionais, encontram-se desde logo inscritos no n. ${ }^{\circ} 2$ do art. $^{\circ}$ 6. ${ }^{\circ}$ da Constituição Política de 1933 e no Estatuto do Trabalho Nacional, o qual no seu art. ${ }^{\circ} 48 .^{\circ}$ refere que em face do princípio de proteção às vitimas de acidentes de natureza profissional derivava, por via de regra responsabilidade, para as entidades patronais.

Embora assente numa conceção assistencialista, caritativa e corporativa, ao estilo bismarckiano, o Estado Novo implementou pela primeira vez em Portugal, um modelo de assistência social que, embora de forma incipiente, procurava garantir proteção social aos cidadãos nacionais. Neste contexto, são publicados os Decretos de 23 de setembro de 1933, que criavam os Grémios, os Sindicatos, as Casas do Povo, as Casas Económicas e o Instituto do Trabalho e da Previdência.

Da organização administrativa do Instituto do Trabalho e da Previdência, criava-se a Repartição das Casas Económicas e a Repartição da Previdência Social e a 
Inspeção de Previdência Social. A organização da Previdência Social ficava completa com a publicação da Lei n. ${ }^{\circ} 1884$ de 16 de março de 1835.

O final da II Guerra Mundial trouxe alterações significativas no domínio da proteção social, com o Plano Beveridge e o impulso dos direitos sociais nos estados democráticos europeus. E, ainda que o regime português se revelasse avesso à internacionalização, o certo é que a pressão social interna, alguma desorganização dos mecanismos corporativos da previdência, a industrialização acompanhada pelo desenvolvimento do setor terciário, a diminuição progressiva do peso económico da agricultura, o êxodo rural verificado a partir dos anos 50 para as grandes cidades do litoral, com a intensificação dos fenómenos da litoralização e da urbanização crescente nas cidades, a restruturação do mercado laboral, com a inserção da mulher no mercado de trabalho, o aumento progressivo da classe média e o aumento exponencial do consumo, conduziram à necessidade de reforma do sistema da previdência social. Esta reforma seria concretizada pela Lei n. ${ }^{\circ}$ 2115, de 18 de junho de 1962.

A reorganização supracitada, ainda que sem estar em consonância com algum dos modelos de Estado de bem-estar já então em vigor na Europa, afirmava-se por ter uma dimensão universalista, considerando como objeto das prestações não apenas os trabalhadores, mas também, os seus familiares e dedicava uma especial atenção às pensões, por morte e invalidez e à cobertura de riscos especiais.

No decurso da Lei n. 2115 , de 18 de junho de 1962, são criadas também um conjunto de instituições de proteção social, como sejam, a Caixa Nacional de Seguros de Doenças Profissionais, (Decreto-Lei n. 44 307, de 27 de abril de 1962), a Federação de Caixas de Previdência e Abono de Família, (Portaria n. 22 451, de 13 de janeiro de 1967), e aprovava o regulamento geral das Caixas Sindicais de Previdência, fixando a sua estrutura, funcionamento e esquemas de benefício (Decreto n. ${ }^{\circ} 45266$, de 23 de setembro).

Criava-se a Caixa Nacional de Pensões (Portaria n. 21 546, de 23 de setembro de 1965), que integrava no seu âmbito os beneficiários das caixas de previdência e abono de família protegidos nas eventualidades de invalidez, velhice e morte.

A Caixa Central de Segurança Social dos Trabalhadores Migrantes, (Decreto-Lei n. 46 813, de 30 de dezembro de 1965), assegurando as funções de organismo de ligação entre as instituições portuguesas de previdência e as suas congéneres de países aos quais Portugal se encontrava ligado por instrumentos internacionais em matéria de Segurança Social. Finalmente, aprovava-se o regulamento geral das Caixas de Reforma ou Previdência (Decreto n. ${ }^{o} 46$ 548, de 23 de setembro de 1965).

A década de 70, viria a ser decisiva nas alterações ao nível da proteção social. Desde logo, com a reorganização dos serviços do Ministério da Saúde e Assistência, e a criação da Direção Geral de Assistência Social (Decreto-Lei n.o 413/71, de 27 de setembro). Altera-se a designação da antiga Direção-Geral da Previdência e Habitações Económicas, que passa a designar-se Direção-Geral da Previdência.

A Direção Geral de Assistência Social, transitaria do Ministério das Corporações e Previdência Social (Decreto-Lei n. ${ }^{\circ} 584 / 73$, de 6 de novembro, decorrente do 
expresso no preâmbulo do Decreto-Lei n. ${ }^{\circ} 413 / 71$, de 27 de setembro), ao mesmo tempo que o Ministério das Corporações e Previdência Social passava a designar-se Ministério das Corporações e Segurança Social, expressão utilizada pela primeira vez (Caeiro, 2015).

A Revolução de 25 de Abril de 1974 produz alterações significativas na estrutura

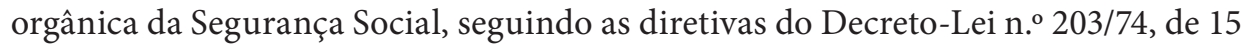
de maio, que estabelece as grandes linhas de orientação do Governo Provisório em matéria de proteção social e, entre elas, a substituição progressiva dos sistemas de previdência e assistência por um sistema integrado de Segurança Social, passando também a ter enquadramento constitucional a partir de 1976, garantindo que "todos têm direito à Segurança Social".

Nos termos constitucionais, procede-se à transferência dos serviços médico sociais da previdência para o âmbito do setor da Saúde, tendo em vista a sua integração no futuro Serviço Nacional de Saúde e é criada a Autoridade Distrital de Segurança Social, designada por «diretor distrital de Segurança Social». No mesmo intuito de reorganização, é criado o Instituto de Gestão Financeira de Segurança Social, (Decreto-Lei n. ${ }^{o}$ 124/77, de 1 de abril). Em 31 de dezembro desse ano, é publicado o Decreto-Lei n. ${ }^{\circ}$ 549/77, de 31 de dezembro, ratificado, com emendas pela Lei n. ${ }^{\circ}$ 55/78, de 27 de julho, que define, em termos profundamente inovadores, a nova estrutura orgânica da Segurança Social, em obediência a três princípios essenciais: integração, descentralização e participação.

A Lei n. ${ }^{\circ} 28 / 84$, de 14 de agosto aprova a primeira lei de bases da Segurança Social, a que se seguiriam a Lei n. ${ }^{\circ}$ 17/2000, de 18 de agosto, e a Lei n. ${ }^{\circ} 4 / 2007$, de 16 de Janeiro, que se mantém em vigor, com as alterações introduzidas pela Lei n. ${ }^{\circ}$ 83/A/2013, de 30 de dezembro.

As prestações sociais introduzidas pela lei de bases, adquirem uma importância fundamental com a criação do subsídio de desemprego para os trabalhadores por conta de outrem com uma taxa contributiva a pagar pelos trabalhadores de $11 \%$ e pelas entidades patronais de $24 \%$. (Loureiro, 2010)

A contemporaneidade recente da Segurança Social, expressa-se na Lei n. ${ }^{0} 83$ A/2013, de 30 de dezembro, a primeira alteração à Lei n. ${ }^{\circ}$ 4/2007, de 16 de janeiro, realiza-se no tempo da intervenção da troika em Portugal e destinava-se a procurar corrigir os seus problemas de sustentabilidade e a ir ao encontro das solicitações desta quanto à necessidade de implementação de um quadro austeritário em Portugal, sobretudo, procurava-se corrigir o valor das pensões a pagar pelo Estado, alterando a idade de reforma e com isto reduzir a despesa associada. Ao mesmo tempo, a lei em apreço, deixa abertas possibilidades de alteração da idade de reforma, em face do princípio da sustentabilidade e da questão demográfica do país.

\section{A Coesão Social}

A coesão social é um tema de grande interesse no contexto da análise dos grupos sociais e da sua interação no seio de um determinado Estado ou agrupamento de 
Estados. Embora com utilização muitas vezes equívoca, o seu conceito sociológico pretende identificar os indivíduos enquanto integrados num grupo social e pela qual se manifesta uma consciência coletiva de pertença, reciprocidade e solidariedade. Desta forma, a coesão social é o elemento chave de qualquer grupo social, que visa sobretudo a cooperação entre os seus membros, de modo a que todos vejam concretizados os seus interesses e necessidades comuns, ainda que individualmente sentidas.

A consideração da coesão social no contexto do Estado, implica a união das forças sociais e das instituições que as sustentam para um fim harmonioso e coerente da vida em comum. Inclui-se necessariamente um grau de solidariedade para a integração social, o que se afigura como um objetivo, muitas vezes difícil, senão mesmo impossível de alcançar de forma plena. E não deixa, em outras circunstâncias, de assumir uma dimensão marcadamente ideológica.

Não se vislumbra no termo coesão social, uma definição clara, tendendo até a ser confundido com outros conceitos que, embora na sua esfera de ação, apresentam objetivos diferenciados. Desde logo, a confusão com o conceito de capital social, o qual representa o conjunto de elementos integrantes de uma sociedade, comunidade ou organização e que aumentam a sua eficácia, por facilitarem a ação conjunta dos indivíduos na realização de objetivos comuns. É, nestes termos, um potenciador de coesão e locomoção social, ao facilitar a associação de indivíduos com uma determinada orientação e direção.

Outro conceito próximo de coesão social é o de integração social, entendida como o processo que possibilita a obtenção de pelo menos, um nível mínimo de bem-estar de acordo com determinados padrões de desenvolvimento (Beccaria, 2007).

A ética social, também é comummente usada no sentido de coesão social, mas ela é, principalmente, uma sua dimensão ao agregar a comunidade dos valores, o consenso sobre os mínimos normativos e sociais, a solidariedade, etc.

Ora, afastados estes conceitos, podemos assumir que, por coesão social, se entende a dialética entre mecanismos instituídos de inclusão e exclusão social e as respostas, perceções e disposições dos cidadãos em face do modo como esses mecanismos funcionam. Nestes termos, a coesão social está associada a um acesso equilibrado da população aos resultados do progresso económico, mediante políticas corretivas da distribuição desigual de rendimentos e aposta na qualidade de vida dos cidadãos.

Dos mecanismos de inclusão social, destacam-se o emprego, os sistemas educacionais, os direitos e as políticas para a promoção da equidade, o bem-estar e a proteção social. Os comportamentos, são entre outros, a confiança nas instituições, o capital social, o sentimento de pertença e a solidariedade.

Os resultados são o acesso aos serviços públicos básicos, universalização do acesso à educação, à saúde, ao saneamento, à habitação condigna, o acesso à energia elétrica, aos transportes, à comunicação, aos direitos humanos, à proteção à criança e ao idoso e ao trabalho.

Fundamental, também, no atual desenvolvimento dos Estados mais desenvolvidos, é a consideração da boa governança para a promoção da coesão social. Com 
efeito, impõe-se a transparência das instituições e dos governos, o combate à corrupção, a participação dos cidadãos na vida e decisões públicas, a accountability, a eficácia, a eficiência e a racionalidade na gestão dos recursos públicos e na respetiva distribuição (Federal, 2018).

Deve destacar-se que um instrumento fundamental do Estado para a promoção da coesão social é a Segurança Social, enquanto mecanismo que pretende promover a redução das desigualdades, a luta contra a pobreza e a melhoria das condições de vida dos cidadãos. Desta forma, surge a crescente necessidade de refletir sobre este tema, na tentativa de reforçar as políticas públicas, garantindo a coesão e solidariedade.

É, tendo por base o conceito de coesão social e o mecanismo privilegiado para o alcançar, a Segurança Social, que vamos em busca de uma resposta para aferir da existência ou não de coesão social, recorrendo à análise dos indicadores disponíveis para avaliar da distribuição do rendimento e das desigualdades em Portugal, no período de 2009 a 2017.

Os indicadores da OCDE apenas se encontram disponíveis a partir de 2013, pelo que usaremos neste caso apenas este período. Para todos os efeitos, esta reflexão visa dar resposta à existência ou não, de um ideal coeso da sociedade, e avaliar como o conjunto dos instrumentos aplicados em Portugal tiveram ou não um resultado eficaz e eficiente na promoção da coesão social (OCDE, 2017).

Procedemos à elaboração de um quadro, no qual, destacamos um conjunto de indicadores (sujeitos a melhoria e a acréscimo de outros que eventualmente se considerem importantes), a partir dos quais pensamos ser possível averiguar do grau de coesão social existente num determinado país, em determinado período de tempo.

Em face dos indicadores considerados e da sua disponibilização, procedemos à comparação com a média da OCDE e, escolhemos desta organização o país europeu com o indicador mais elevado e, os indicadores cujos dados estão disponíveis apenas para Portugal, o seu tratamento refere-se apenas ao caso nacional. 
Quadro 1. Indicadores de Coesão Social

\begin{tabular}{|c|c|}
\hline Dimensão & Indicadores \\
\hline \multirow{8}{*}{ Cidadania } & Qualidade de vida \\
\hline & Satisfação com a vida \\
\hline & Participação eleitoral \\
\hline & Habitação sem instalações sanitárias básicas \\
\hline & Qualidade de suporte na comunidade \\
\hline & Participação na vida pública \\
\hline & Taxa de analfabetismo \\
\hline & Índice de bem-estar \\
\hline \multirow{12}{*}{ Emprego e rendimento } & Taxa de emprego \\
\hline & Insegurança no mercado de trabalho \\
\hline & Taxa desemprego longa duração \\
\hline & Ganhos pessoais \\
\hline & Rendimento disponível agregado familiar \\
\hline & Riqueza líquida agregado familiar \\
\hline & Evolução real do rendimento equivalente \\
\hline & Salário médio mensal \\
\hline & Remuneração base e ganho por sexo \\
\hline & Remuneração total por nível de qualificação \\
\hline & Remuneração total e por setor de atividade \\
\hline & Remuneração total por nível de qualificação na Administração Pública \\
\hline \multirow{9}{*}{ Desigualdade e Pobreza } & Evolução da desigualdade \\
\hline & Indicadores de desigualdade \\
\hline & Indicadores de desigualdade do rendimento \\
\hline & Desigualdades salariais \\
\hline & Taxa de privação material severa \\
\hline & Limiar da pobreza \\
\hline & Taxa de intensidade da pobreza \\
\hline & Taxa de risco de pobreza \\
\hline & Taxa de risco de pobreza por grupo etário \\
\hline
\end{tabular}

Fonte: Elaboração própria (adaptado de vários autores).

\subsection{Coesão Social e Cidadania}

A OCDE avalia o nível de satisfação com a vida, através da utilização de uma escala de 0 a 10, considerando o 0 , como o limiar inferior da qualidade de vida e 10 o valor mais elevado, e definindo a média dos países integrantes daquela organização em 6,5 . O nível de satisfação dos cidadãos portugueses é, neste caso, claramente inferior quer à média dos países, quer ao valor apresentado pelo país em que o indicador é o mais elevado, no caso concreto, a Noruega, (gráfico 1). 


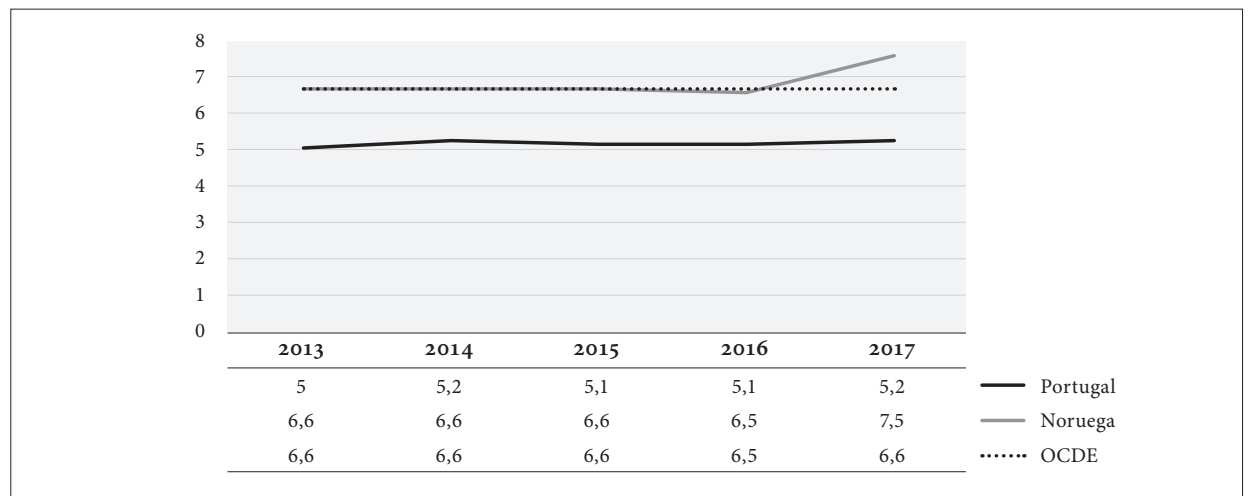

Gráfico 1. Nível de satisfação com a vida

Fonte: OCDE Better Life Index, Proteção Social e bem-estar (2013-2017).

De uma forma geral, entre 2013 e 2016, em Portugal o grau de satisfação é inferior à média da OCDE, fruto dos impactos negativos na vida da população e, particularmente no caso português, dos reflexos da austeridade no período em causa. Os desequilíbrios que se têm feito sentir em Portugal, nesta última década, tornaram difícil alcançar um equilíbrio e a convergência dos indicadores macroeconómicos à escala da União Europeia.

A participação eleitoral é, particularmente, um indicador a destacar no que diz respeito ao interesse da comunidade pela Nação. Podemos averiguar a incidência eleitoral e a sua variação no período considerado: Portugal, ao nível da participação eleitoral, está claramente abaixo da média e com um sucessivo decréscimo da participação a partir de 2013 (gráfico 2).

Quanto às instalações sanitárias básicas, de uso generalizado em todas as habitações, Portugal continua abaixo da média dos países da OCDE, com cerca de 1\% da população portuguesa que não dispõe em 2017, de instalações sanitárias básicas, afetando quase 100.000 pessoas, e mais longe do país que na Europa apresenta o melhor indicador, a Holanda (gráfico 3).

Considerando a existência de uma rede de suporte na comunidade, através da qual os cidadãos têm a perceção de que em situações de dificuldade, lhes é dispensada ajuda por amigos ou familiares, podemos ver que em Portugal se tem uma perceção mais baixa do que na média dos países da OCDE e mais acentuada, se comparada com o país com a perceção mais elevada, a Islândia (gráfico 4).

Vimos esta perceção com alguma perplexidade, pois tradicionalmente as redes de vizinhança em Portugal eram de grande qualidade. Fica, em nosso entender, a dever-se em grande parte à vida citadina e à redução da população nos meios rurais.

No que se refere à participação formal e informal dos cidadãos na vida pública e na tomada de decisão a situação em Portugal é, visivelmente, mais desfavorecida do que na média da $\operatorname{OCDE}(6,5)$ e, mais ainda, se em comparação com o país onde o ní- 


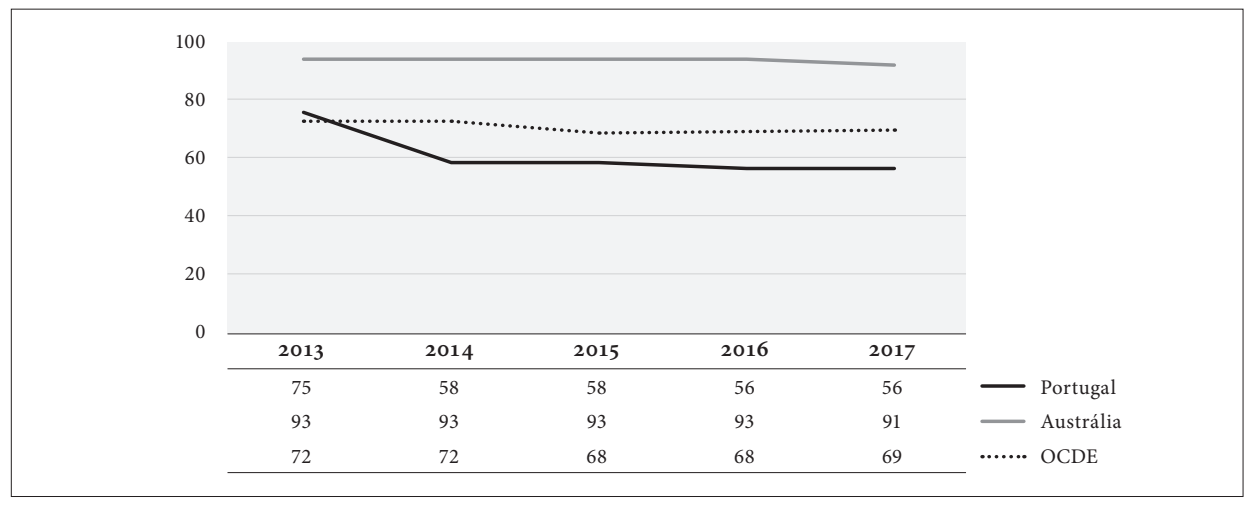

\section{Gráfico 2. Participação eleitoral (\%)}

Fonte: OCDE Better Life Index, Proteção Social e bem-estar (2013-2017).

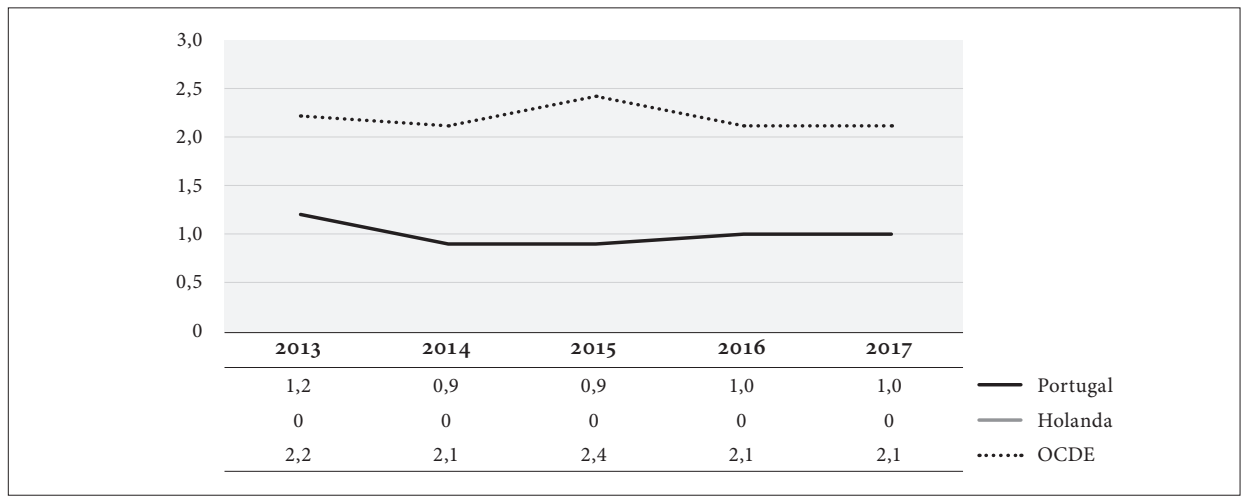

Gráfico 3. Habitação sem instalações sanitárias básicas

Fonte: OCDE, Better Life Index, Proteção Social e bem-estar (2013-2017).

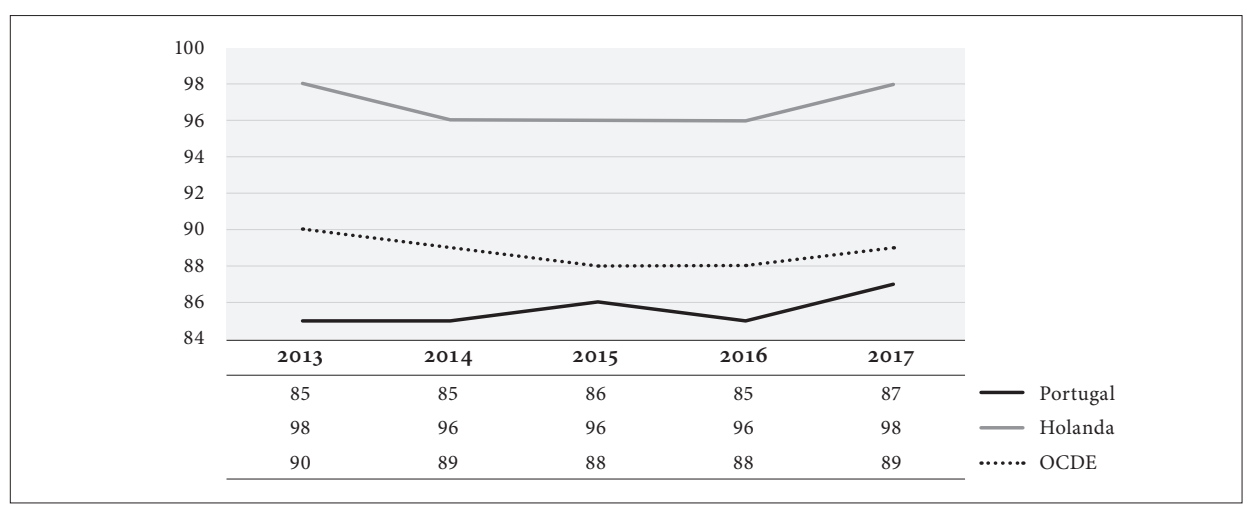

Gráfico 4. Qualidade de suporte na comunidade (\%)

Fonte: OCDE, Better Life Index, Proteção Social e bem-estar (2013-2017). 
vel de participação é mais elevado, o Reino Unido, com um valor de respetivamente 11,5 (gráfico 5).

O índice de bem-estar, permite perceber uma dupla dinâmica ao nível das condições de vida dos cidadãos nacionais: as condições materiais de vida e a qualidade de vida. No primeiro, tem-se em atenção entre outros, o bem-estar económico, a vulnerabilidade económica e a remuneração do trabalho. No segundo, entre outros indicadores, consideram-se o balanço vida e trabalho, as relações sociais e bem-estar subjetivo e a participação cívica e governação. O somatório destes dois índices permite entender a dimensão do bem-estar dos cidadãos nacionais (quadro 2).

Verificou-se entre 2009 e 2017, um aumento crescente do bem-estar global dos cidadãos, mas a sua vulnerabilidade económica mantém-se patente, tendo alcançado o resultado mais baixo em 2013, corrigindo a partir daqui e alcançando o valor mais elevado em 2017. Igualmente, com a remuneração do trabalho e o bem- estar económico, cujo valor mais baixo é alcançado em 2013, corrigindo a partir daqui o grau de satisfação. De forma diferente dos outros indicadores, o bem-estar económico tem-se mantido positivo desde 2009.

Quanto ao balanço vida/trabalho, desde 2011 que tem vindo a decrescer, registando-se em 2017 o valor mais baixo. Diversamente, as relações sociais e bem-estar subjetivo e a participação cívica e governação, têm vindo a aumentar desde 2011, tendo este último indicador alcançado em 2017, um resultado altamente positivo. As expetativas dos cidadãos nacionais, estão desde 2014 em alta, ainda que tais expetativas, na maior parte dos outros indicadores, não serem positivas.

\subsection{Coesão Social, Emprego e Rendimento}

Para determinar o nível de coesão social importa também avaliar o emprego e a distribuição do rendimento, pois a distribuição desigual destes indicadores é um forte entrave à equidade social.

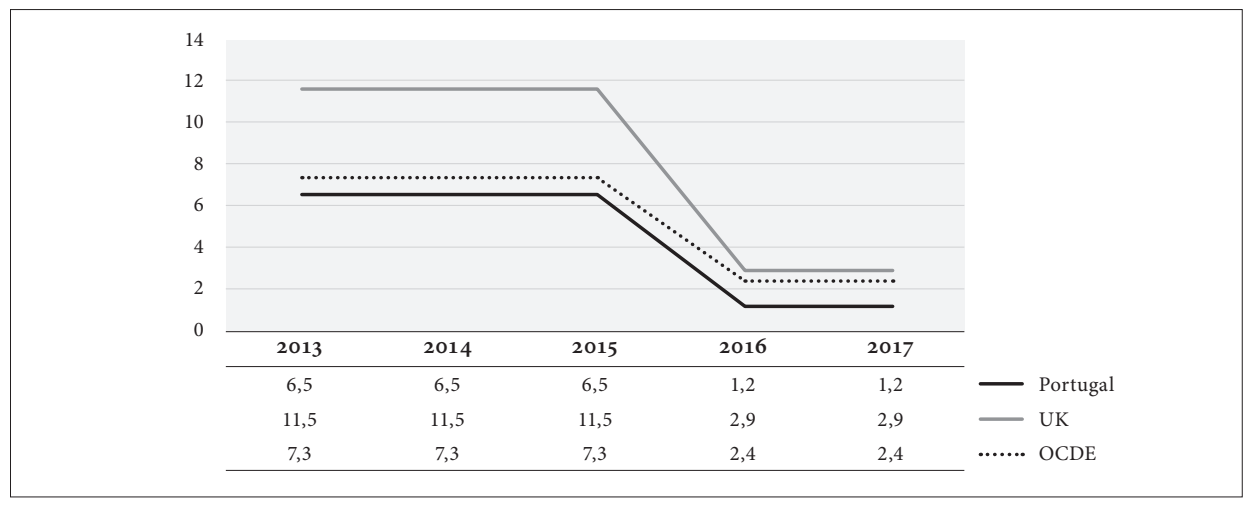

Gráfico 5. Participação na vida pública

Fonte: OCDE, Better Life Index, Proteção Social e bem-estar (2013-2017). 
Quadro 2. Índice de Bem-estar

\begin{tabular}{ccccc}
\hline & \multicolumn{4}{c}{ Índice condições materiais de vida } \\
\cline { 2 - 5 } & $\begin{array}{c}\text { Índice global } \\
\text { bem-estar }\end{array}$ & $\begin{array}{c}\text { Bem-estar } \\
\text { económico }\end{array}$ & $\begin{array}{c}\text { Vulnerabilidade } \\
\text { económica }\end{array}$ & $\begin{array}{c}\text { Remuneração } \\
\text { trabalho }\end{array}$ \\
\hline 2009 & 106,5 & 108,3 & 90,1 & 89,9 \\
2011 & 108,6 & 105,8 & 85,3 & 75,7 \\
2013 & 111,3 & 103,9 & 75,9 & 71,1 \\
2015 & 119,9 & 107,9 & 83 & 74,9 \\
2017 & 131,4 & 113,1 & 94,3 & 85,2 \\
\hline
\end{tabular}

Índice qualidade de vida

\begin{tabular}{cccc}
\cline { 2 - 3 } & Balanço vida/trabalho & Relações sociais e bem estar subjetivo & Participação cívica e governação \\
\hline 2009 & 110 & 96,1 & 96,1 \\
2011 & 112,4 & 98,2 & 93,6 \\
2013 & 106,5 & 98 & 116,8 \\
2015 & 104,2 & 103 & 148,9 \\
2017 & 99,9 & 112 & 173,3 \\
\hline
\end{tabular}

Fonte: PORDATA

A taxa de emprego entre Portugal e a média dos países da OCDE, não se encontra muito desajustada. No entanto, se considerarmos o país na Europa com taxa de emprego mais elevada, a Islândia, a discrepância já é bem evidente, apresentando esta em 2017, uma taxa de 86\%, enquanto Portugal apresenta uma taxa de 65\% (gráfico 6).

A situação de desemprego de longa duração (um ano ou mais em situação de desemprego), reflete sobretudo, um problema da reduzida qualificação de muitos dos trabalhadores e da idade em que são confrontados com a situação de desemprego. Neste caso, Portugal encontra-se abaixo da média da OCDE e ainda mais distante da Islândia, o país com a taxa de desemprego de longa duração mais baixa $(0,26 \mathrm{em}$ 2017). A idade continua a ser um estigma no mercado de trabalho nacional, tal como a reduzida qualificação profissional (Gráfico 7).

Quanto à forma como os trabalhadores vêm a situação laboral do ponto de vista da manutenção do emprego, a perceção da segurança por parte dos trabalhadores é bastante limitada em Portugal (6,14\%), quando comparada com a média da OCDE e com a Suíça, que apresenta uma taxa de 1,8\% (Gráfico 8).

Ao nível do rendimento, a sua distribuição tem uma influência substancial na promoção da coesão social. A diferença entre o rendimento líquido do agregado familiar em Portugal é, nitidamente, inferior à média da OCDE, no decurso do período considerado e ainda mais evidente, quando comparado com o país europeu com o maior rendimento, a Suíça. A diferença para a média comunitária ronda, no período cerca de $30 \%$, e, em comparação com a Suíça, a diferença é de cerca de $71 \%$. Fica clara a discrepância (Gráfico 9). 


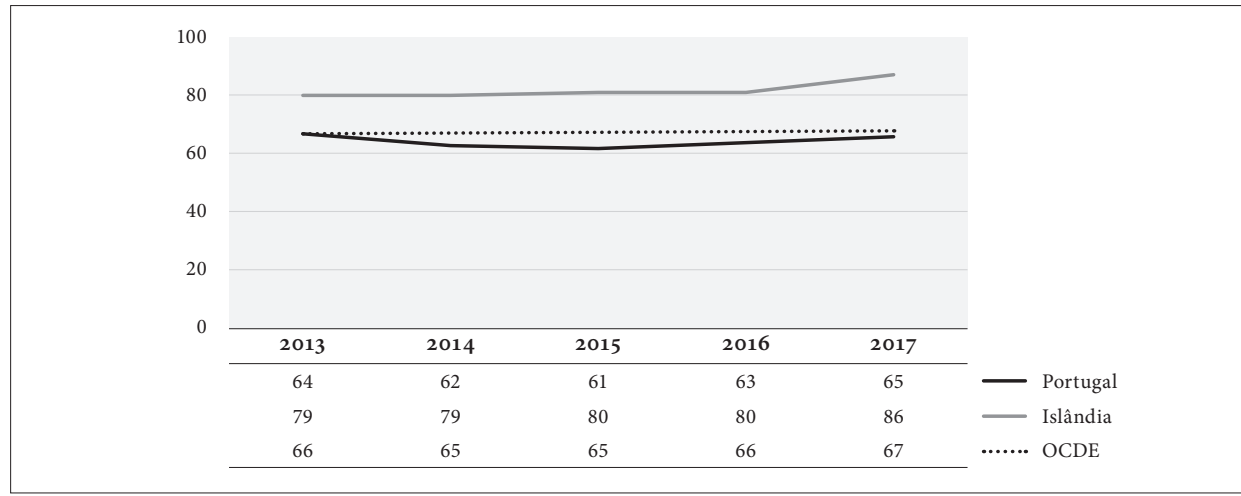

Gráfico 6. Taxa de emprego (\%)

Fonte: OCDE Better Life Index, Proteção Social e bem-estar (2013-2017).

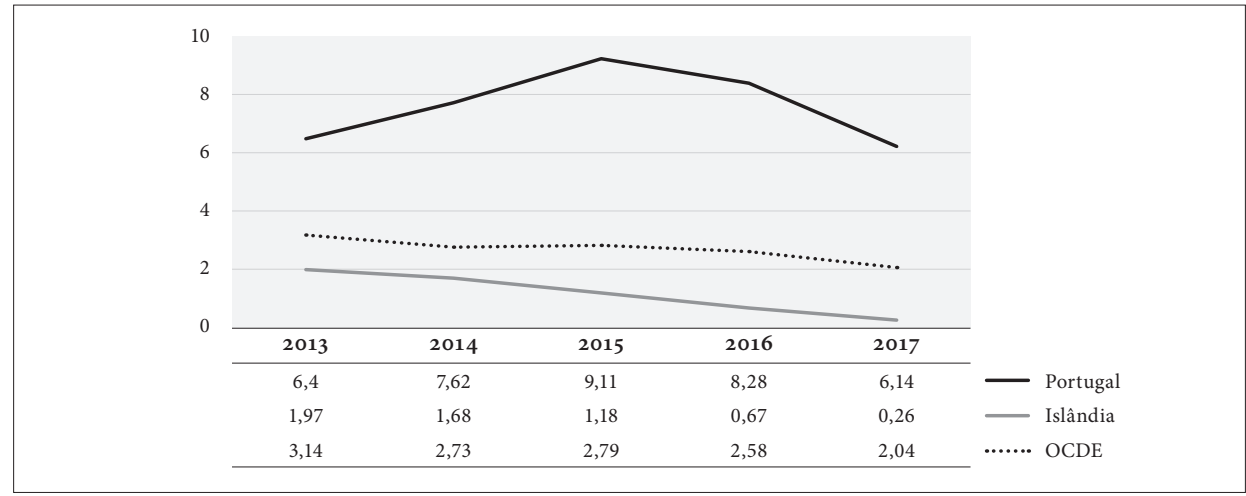

Gráfico 7. Taxa de desemprego longa duração (\%)

Fonte: OCDE Better Life Index, Proteção Social e bem-estar (2013-2017).

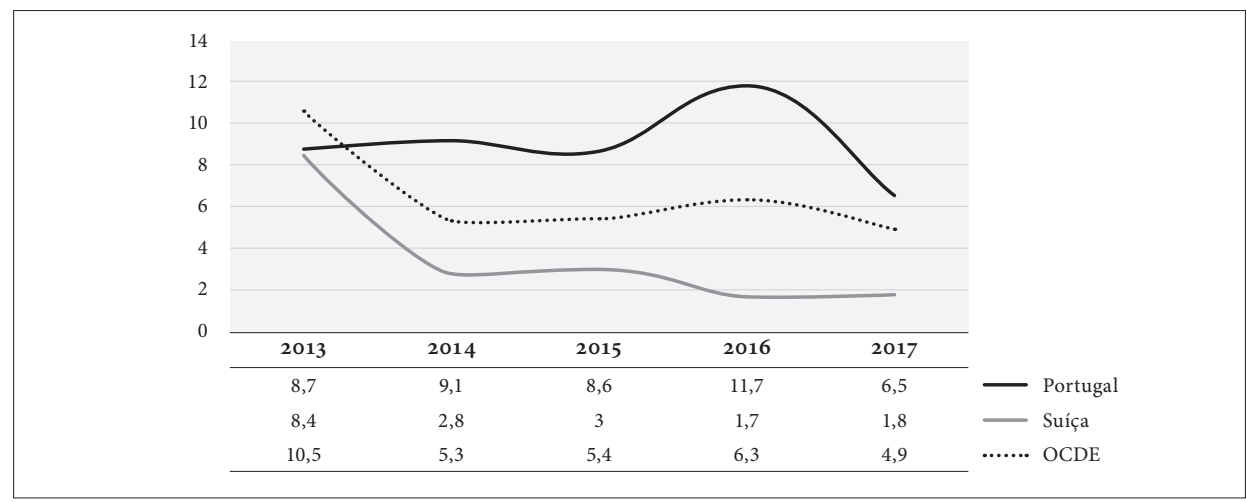

Gráfico 8. Insegurança no mercado de trabalho (\%)

Fonte: OCDE Better Life Index, Proteção Social e bem-estar (2013-2017). 


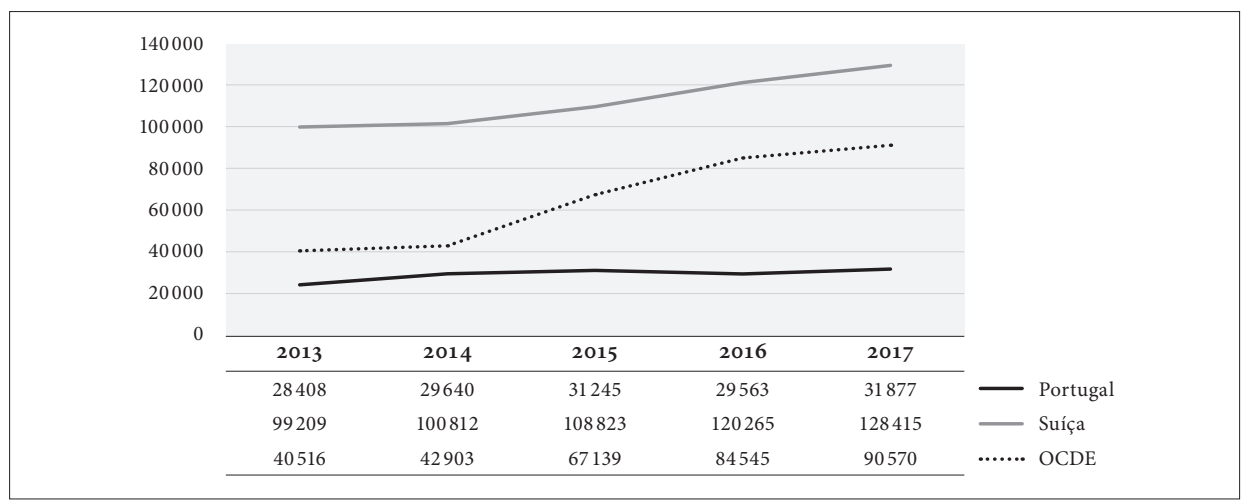

Gráfico 9. Rendimento líquido do agregado familiar (Euros/anuais)

Fonte: OCDE Better Life Index, Proteção Social e bem-estar (2013-2017).

No caso do rendimento disponível do agregado familiar, este é inferior à média da OCDE, em cerca de $32 \%$ e, ainda mais em relação ao Luxemburgo, cujo rendimento disponível é cerca de 68\% mais alto que em Portugal (Gráfico 10).

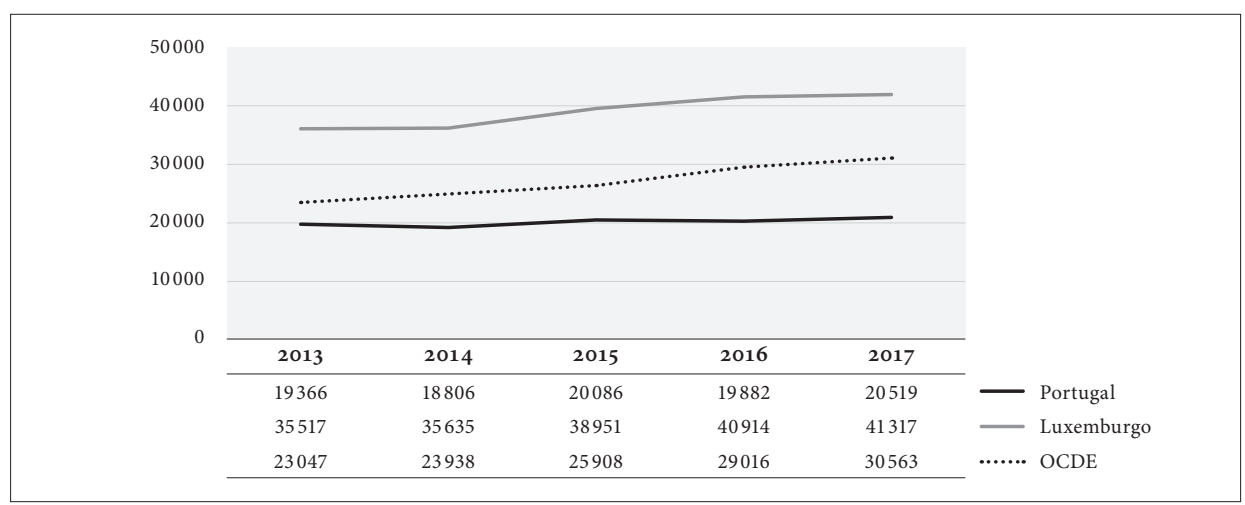

Gráfico 10. Rendimento disponível do agregado familiar

Fonte: OCDE Better Life Index, Proteção Social e bem-estar (2013-2017).

Quanto ao salário médio mensal, entre 2009 e 2017, cresceu apenas cerca de 8\%, passando respetivamente de $867,50 €$ para $943,00 €$. O salário médio das mulheres é sempre inferior ao dos homens, e mais evidente ainda, sempre abaixo do salário médio nacional (Gráfico 11). 


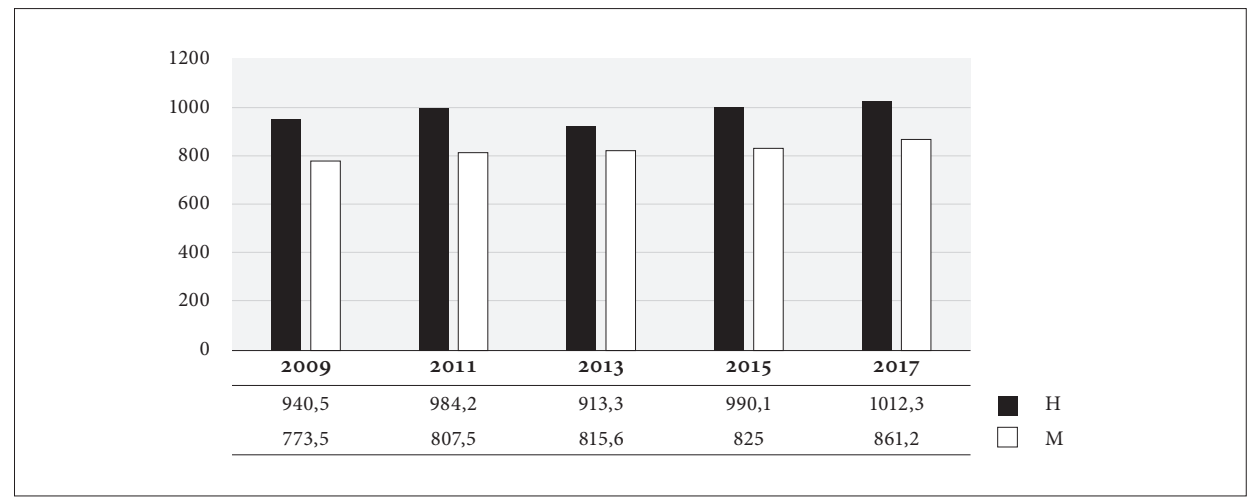

Gráfico 11. Remuneração por sexo

Fonte: PORDATA.

Em Portugal, a forte redução do emprego, decorrente da política de austeridade, contribuiu em larga escala para a descida dos salários, sobretudo entre 2011 e 2013 e, de forma artificial, o valor do rendimento salarial se ter mantido estacionário em alguns dos casos. Da correlação entre os valores do rendimento mínimo mensal garantido e os valores do salário médio da população portuguesa, são notórias as discrepâncias. O salário que é ganho, em média pela população, é quase o dobro do valor do salário mínimo nacional em 2015. Donde, em 2015 cerca de 612 mil trabalhadores recebiam o salário mínimo, o que significa que cerca de $20 \%$ da população portuguesa vivia na época com 530 euros mensais (Quadro 5).

Quadro 5. Indicadores de desigualdade de rendimento

\begin{tabular}{lrrrrr}
\hline & \multicolumn{1}{c}{2009} & 2011 & 2013 & 2015 & 2017 \\
\hline Salário mínimo (mensal) & 450,00 & 475,00 & 485,00 & 530,00 & 649,00 \\
Salário mínimo (anual) & 6300,00 & 6790,00 & 6790,00 & 7420,00 & $9.086,00$ \\
Rendimento Mediano monetário anual & 8678,00 & 8323,00 & 8229,00 & 9071,00 & $13.202,00$ \\
Rendimento Mediano monetário mensal & 619,86 & 594,50 & 587,79 & 647,93 & 943,00 \\
Salário médio & 867,50 & 905,10 & 911,50 & 913,90 & 943,00 \\
\hline
\end{tabular}

Fonte: Instituto Nacional de Estatística, Indicadores Sociais.

Vejamos também a relação entre salários no setor privado e na Administração Pública, no que respeita aos quadros superiores, quadros médios, trabalhadores qualificados e não-qualificados.

Os quadros superiores do setor privado sofreram uma redução salarial no decurso do período de crise, que se mantém até 2017 , enquanto os trabalhadores qualificados 
e não-qualificados, viram pelo contrário, os seus salários relativamente melhorados no decurso do período.

$\mathrm{Na}$ Administração Pública, pelo contrário e, apesar de um ligeiro decréscimo do valor salarial, no auge da crise (2013), verificou-se uma tendência acentuada de crescimento, suplantando os salários praticados no setor privado.

A tendência de aumento de salários na Administração Pública é ainda mais evidente em 2017, com uma diferença de cerca de $25 \%$ face ao setor privado. O aumento salarial da função pública entre 2009 e 2017 foi de 23,8\%, enquanto que no setor privado, se verificou uma redução salarial de cerca de 4\% (Quadro 6).

Quadro 6. Remuneração mensal comparada (Administração Pública/S. Privado)

\begin{tabular}{ccccccccc}
\hline & \multicolumn{2}{c}{ Quadros superiores } & \multicolumn{2}{c}{ Quadros médios } & \multicolumn{2}{c}{ Qualificados } & \multicolumn{2}{c}{ Não qualificados } \\
\hline & S. Privado & A. Pública & S. Privado & A. Pública & S. Privado & A. Pública & S. Privado & A. Pública \\
\hline 2009 & $2.485,6$ & $2.435,2$ & $1.760,3$ & $1.778,9$ & 846,20 & 793,20 & 615,40 & 554,00 \\
2011 & $2.434,7$ & $2.875,6$ & $1.705,0$ & $1.675,1$ & 880,30 & 822,70 & 65,70 & 685,00 \\
2013 & $2.383,3$ & $2.724,5$ & $1.709,6$ & $1.638,5$ & 884,10 & 829,10 & 658,80 & 693,60 \\
2015 & $2.370,5$ & $3.127,1$ & $1.702,2$ & $2.230,5$ & 893,90 & 832,80 & 671,20 & 675,90 \\
2017 & $2.390,5$ & $3.196,8$ & $1.719,1$ & $1.807,4$ & 908,50 & 822,10 & 715,50 & 768,30 \\
\hline
\end{tabular}

Fonte: PORDATA.

\subsection{Coesão Social, Desigualdade e Pobreza}

A desigualdade nos rendimentos mais baixos tem uma incidência imediata na pobreza e nas desigualdades do rendimento, verificando-se um aumento significativo na taxa de intensidade da pobreza entre 2009 e 2013 (6\%), e da taxa de risco de pobreza, antes qualquer transferência, (43,40\%) em 2009 (47,80\%) em 2013 (Quadro 7).

Quadro 7. Riscos de pobreza

\begin{tabular}{cccccc}
\hline \multicolumn{2}{c}{ Taxa risco de pobreza } & & \\
\hline $\begin{array}{c}\text { Taxa intensidade } \\
\text { da pobreza }\end{array}$ & $\begin{array}{c}\text { Limiar da } \\
\text { pobreza }\end{array}$ & $\begin{array}{c}\text { Antes de } \\
\text { qualquer } \\
\text { transferência }\end{array}$ & $\begin{array}{c}\text { Após } \\
\text { transferência } \\
\text { pensões }\end{array}$ & $\begin{array}{c}\text { Após } \\
\text { transferência } \\
\text { social }\end{array}$ \\
\hline 2009 & 22,70 & 5.207 & 43,40 & 26,40 & 17,90 \\
2011 & 24,10 & 4.994 & 45,40 & 25,30 & 17,90 \\
2013 & 30,30 & 4.937 & 47,80 & 26,70 & 19,50 \\
2015 & 26,70 & 5.269 & 46,10 & 25,00 & 19,00 \\
2017 & 24,50 & 5.610 & 43,70 & 22,70 & 17,30 \\
\hline
\end{tabular}

Fonte: PORDATA. 
É, ao nível das questões da pobreza e da desigualdade, que a segurança social tem ou deve ter uma importância determinante. $\mathrm{O}$ amplo leque dos seus subsídios, deveria ter como resultado uma redução substancial daqueles indicadores, equilibrando os desajustamentos verificados. Mas, ainda assim, tal não é conseguido, pelo que, após as transferências sociais e as pensões, se mantêm elevadas as taxas de pobreza e de desigualdade. Com efeito, não se consegue reduzir a dimensão da desigualdade e da pobreza com recurso ao leque enorme de subsídios a partir da segurança social. Talvez, seja este o problema o fundamental, e que implica uma análise mais detalhada e profunda sobre a tipologia dos subsídios, o seu número e o seu valor, para analisarmos a sua eficácia. Sem tempo para tratar aqui esta questão, preconizamos, todavia, uma possibilidade da sua redução em número e tipologia e uma orientação mais eficiente, no sentido da efetiva correção das desigualdades e da pobreza (Coelho, 2013).

\section{Conclusão}

Aceitamos que não existe coesão social em Portugal e, a partir de 2009, a intensidade da pobreza foi crescente até ao ano de 2016, com as consequências sociais derivadas do processo de ajustamento e manifestadas por um aumento exponencial de população em risco de pobreza e o aumento da taxa de intensidade da pobreza (4,3\%). Após as transferências sociais realizadas a partir de fundos do orçamento do Estado, a correção que se verifica não permite reduzir um número significativo de pobres ou em risco de pobreza. A correção direta de 4,8\% em 2009, 6,2\% em 2011, 10,8\% em 2013 e 8,3\% em 2016, demonstra o carácter prevalecente da elevada taxa de pobreza.

É curioso ressaltar o facto de ser nos anos de crise mais profunda (2011 a 2013) onde a correção é mais intensa, inferindo-se que o recurso a políticas públicas de emergência do Governo de então evitaram a possibilidade de uma maior taxa de pobreza (são exemplo, entre outras medidas, o Plano de Emergência Social e a criação das cantinas sociais).

O limiar da pobreza (60\% da mediana do rendimento) que foi acompanhando a desvalorização dos salários ao longo dos anos de crise referidos, servindo para perceber a incoerência das políticas públicas destinadas a combater a pobreza.

Em Portugal, o limiar de pobreza de cerca de 389€, em 2016, coloca nas estatísticas cerca de 2.000.000 pessoas em risco de pobreza, deixando ainda de fora um número certamente elevado de pessoas cujo rendimento terá superado de forma relativa aquele limiar.

A incoerência das estatísticas e da sua interpretação literal permite um olhar errado sobre a verdadeira situação da pobreza. Esta é uma "armadilha" que não mostra de forma completa a efetiva deterioração das condições de vida da população, tendendo a subestimar o real agravamento daquelas situações.

A coesão social, para refletir um quadro social o mais equitativo e justo possível, pela via da redução das desigualdades, eliminação da pobreza e pela criação de mecanismos que promovam a cidadania e a participação dos cidadãos, nunca será 
alcançada de forma plena, sem a existência de políticas públicas sociais que, de forma redistributiva, permitam aos mais fragilizados a obtenção de capacidades, competência e meios materiais, para alcançar os meios indispensáveis para a melhoria do seu bem-estar e da sua qualidade de vida. Da análise a que procedemos ao longo do presente texto, em Portugal, não apenas não foram alcançados resultados aceitáveis de coesão social, como se verificou a sua deterioração. A desigualdade social aumentou e os mecanismos de proteção social, não surtiram o efeito desejado, associado a ineficaz participação social e de cidadania, não se verificando em Portugal uma coesão social de fato.

Data de receção: 23/07/2019

Data de aprovação: 18/12/2019

\section{Referências}

Beccaria, A. U. (2007). El Panorama social de América Latina. Santiago de Chile: Naciones Unidas.

Caeiro, J. C. (2015). Estado Social, Políticas Públicas e Política Social. Lisboa: ISCSP.

Coelho, M. (2013). Segurança Social: Situação actual e perspectivas de reforma. Lisboa: Diário de Bordo.

Federal, G. (2018). Guia da Política de Governança Pública. Brasília: Governo Federal Brasil.

Loureiro, J. C. (2010). Adeus ao Estado Social. A segurança Social entre o crocodilo da economia e a medusa da ideologia dos "direitos adquiridos". Coimbra: Coimbra Editora.

OCDE. (2017). Relatórios Económicos da OCDE. Lisboa: OCDE.

Pereirinha, J. (2016). "Pobreza e novos riscos sociais em Portugal: uma análise da despesa social" in C. A. Luz, Políticas Sociais em Tempos de Cise - Perspectivas, Tendências e Questões Críticas. Lisboa: Sílabo. 


\section{Sobre o autor}

JOAQUim MANUel Croca CAEIRo é Professor Catedrático convidado do Instituto Superior de Ciências Sociais e Políticas da Universidade de Lisboa, onde leciona disciplinas relacionadas com a História da Administração Pública, Políticas Públicas e Seminário de Investigação e é Coordenador da Escola de Desenvolvimento Local do mesmo Instituto. É doutor em Ciência Política, mestre em Ciência Política e licenciado em Gestão e Administração Pública pelo Instituto Superior de Ciências Sociais e Políticas da Universidade de Lisboa e em Direito, pela Universidade Lusíada de Lisboa. Desempenhou funções em vários serviços públicos, nomeadamente Vogal do Conselho Diretivo de Segurança Social e Sub-diretor Geral do Gabinete de Estratégia e Planeamento do Ministério de Solidariedade e Segurança Social, e privados, tendo representado Portugal em Comités da União Europeia.

\section{About the author}

JOAQUim MANUEL CROCA CAeIro is a visiting Full Professor at the Higher Institute of Social and Political Sciences of the University of Lisbon, where he teaches subjects related to the History of Public Administration, Public Policies and Research Seminar and is Coordinator of the Local Development School of the same Institute. He holds a PhD in political science, a master's degree in political science and a degree in management and public administration from the Higher Institute of Social and Political Sciences of the University of Lisbon and, in law, from the Lusíada University of Lisbon. He has served in various public services, including Member of the Social Security Board of Directors and Deputy Director General of the Strategy and Planning Office of the Ministry of Solidarity and Social Security, and private, having represented Portugal on European Union Committees. 